\title{
'No-one runs away for no reason': Understanding safeguarding issues when children and young people go missing from home
}

\author{
Louise Hill ${ }^{1}$, Julie Taylor ${ }^{2}$, Fiona Richards ${ }^{3} \&$ Susan Reddington $^{3}$ \\ ${ }^{1}$ Centre for Excellence for Looked After Children in Scotland, University of \\ Strathclyde, UK \\ ${ }^{2}$ NSPCC Child Protection Research Centre, University of Edinburgh, UK \\ ${ }^{3}$ NSPCC, UK
}

\begin{abstract}
\end{abstract}
An estimated one in nine children will run away from home or substitute care before their sixteenth birthday in the United Kingdom. This paper explores the safeguarding concerns and responses for children and young people who run away or go missing from home. The majority of children and young people run away from home due to family relationship problems. Running away or being physically absent from home may be due to abuse and neglect. One in eleven children reported being hurt or harmed whilst running away. For some young people, 'running to' a person or situation can present many risks and can be part of a coercive and exploitative relationship. Despite these multiple indicators of risk, there has been little focus on safeguarding policies and practice for children and young people who run away from home. Drawing on a case example of a third sector service using Return Interview Assessments, this paper argues that professionals must ensure that all children and young people who run away or go missing from home are given meaningful opportunities to be listened to, and taken seriously, in order to ensure a wide range of safeguarding concerns can be addressed. (w.c.195) 
Keywords: abuse, neglect, missing children, young runaways

Key Practitioner Messages

- When a child runs away from home, something may be wrong in that child's life.

- Some children run away or are absent from home due to abuse or neglect.

- Some children are 'running to' a place or person, which can place them at even more risk of harm.

- All children who run away need to have an opportunity to talk about what is happening in their life without feeling judged. 


\section{Introduction}

'No-one runs away for no reason', Amie, aged thirteen (DCSF, 2009:1).

There is a recognised gap in response to children and young people who run away from home. In 2006, an All-Party Parliamentary Group (APPG) on Missing Children and Young People was established to improve the support for children and young people who run away from home. Across England, there had been disparity of local responses to the needs of children missing from home compared to children missing from care (Evans et al., 2007). Thus the introduction of statutory guidance for children who run away or go missing from home and care (National Indicator 71 currently under review) 'serves to safeguard all runaways and to redress the imbalance that currently exists between services offered to runaways from the lookedafter population and those who run away from home' (DCSF, 2009:4). Despite this policy intent, children who go missing from home remain overlooked. In 2012 the House of Commons All-Party Parliamentary Group (APPG) for Missing Children and Adults and APPG for Looked after Children and Care Leavers conducted a joint inquiry solely focused on children who go missing from care (Westminster APPG for Missing Children, 2012). Responding to recent inquiries into the sexual exploitation of children and young people (Berelowitz et al., 2012; Chase and Stratham, 2005; Gray and Watt, 2013), political attention has focused almost exclusively on children in residential child care settings; however, a number of them had run away or were missing from family homes.

This article explores the child protection concerns and responses for children and young people who run away or go missing from home. We will refer to this group 
hereon in as 'children' unless we are referring specifically to particular groups. Under section 11 of the Children Act 2004 local authorities have a statutory duty to "safeguard and promote the welfare of children in need" up to the age of 18 years old. When running away, children are strongly and directly indicating that they may require help and support. We argue that professionals are often not responding effectively to the needs of this group and may miss opportunities to protect children. We begin with context, considering the range of definitions, prevalence and known risks facing children who run away or go missing from home. We explore the development of a National Society for the Prevention of Cruelty to Children (NSPCC) Missing Children's service and their use of Return Interview Assessments with children who have run away or been missing from home. In the discussion, we explore how children missing from home remain hidden and what support is needed to meet their needs.

\section{Children who run away or go missing from home}

\section{Definitions}

There is a lack of consensus and definitional clarity used to describe children who run away or are forced to leave home or substitute care (Evans et al., 2007). Wade (2001:4) notes a variety of terms in use across research and policy: 'missing persons, absconders, runaways, thrownaways, sofa surfers, homeless, street children and so on'. A young runaway can be defined as,

'Any young person who spends time away from the family home or substitute care before the age of 16 without the permission of their parents or carers or as a result of being forced to leave' (Wade, 2003: 343). 
In England, the terms 'young runaway and missing in this context refer to children and young people up to the age of 18 who have run away from their home or care placement, have been forced to leave, or whose whereabouts is unknown' (DCSF, 2009:6). Although it is widely recognised that children may 'run away' or be missing for a period during the day, 'runaways' tend to include a definition of staying away from home or care for at least one night (Malloch \& Burgess, 2011). 'Running away' may be an inadequate term for children who may more accurately be described as "running from' fractured and turbulent homes' (Rosenthal et al., 2006:282). Some children define themselves as 'staying away from home', suggesting there may be an important distinction (Rees \& Lee, 2005). Furthermore, the limitation of the term 'runaway' is the inaccuracy in describing the situation for those children who are 'forced to leave'. Rees and Siakeu (2004) use the term 'thrown away' to address specifically the needs of children who are forced to leave home.

A child may also be 'missing' from home without the awareness or concern of parents or carers about their whereabouts. These children may not describe themselves as 'running away' or being forced to leave, however, they experience a disregard for their safety and are inappropriately unsupervised in a community. Indeed in a systematic review of the literature on neglect, Daniel et al. (2011) exposed running away as one potential signal that a child is being neglected. In a study of young runaways' use of a national Message Home helpline, some parents were unaware when contacted that their child had run away (Mitchell, 2003). In particular the neglect of adolescents is of increasing concern (Rees et al., 2011) and there are calls to focus much more attention on their needs (Khadr et al., 2011). 


\section{How many children run away?}

Across the UK there has been a growing evidence base exploring the prevalence, characteristics and experiences of children and young people who runaway from home or care (Mitchell et al., 2003; Raws, 2001; Rees, 2011; Rees \& Lee, 2005; Safe on the Streets Research Team, 1999; Smeaton, 2009; Wade 2001) (The first UK survey of young runaways, Still Running estimated one in nine young people ran away from home overnight on at least one occasion before the age of 16 (Safe on the Streets Research Team, 1999). The study included a self-completed questionnaire by 13000 young people (aged 14 and 15), interviews with 200 young people who had experience of running away or had been forced to leave home and 400 professionals working across agencies who may have contact with young runaways. Further analysis undertaken in Scotland found the same prevalence rates as England (Wade, 2001). Across studies, the peak age for running away was between thirteen and fifteen years old; however, one fifth of children who ran away or were forced to leave home did so before the age of eleven (Wade, 2001). Follow up surveys have indicated a fairly consistent pattern over time (Rees \& Lee, 2005; Rees, 2011). Studies have found little difference in rates of running away across cities, towns and rural settings or different socio-economic areas (Safe on the Streets Research Team, 1999; Wade, 2001; Rees \& Lee, 2005; Franks \& Goswami, 2010; Rees, 2011) although there is a slightly older age of first running away in larger cities. The majority of children will only run away once or twice, do not stay away long and return home safely (Wade, 2003).

Females are slightly more likely to run away than males (Rees, 2011) and young people of mixed ethnic origin have the highest rates of running away. Although a 
small response rate $(<160)$, disabled children had much higher rates of running away overnight, as did the one fifth of children who described themselves as having learning difficulties (Rees, 2011). Similarly Sullivan and Knutson (2000) found higher prevalence rates for disabled children running away, with a significant association to physical and sexual abuse.

Official data on children who are missing from home is limited. The majority of children will not be reported to the police; in the Still Running 3 survey, $70 \%$ of runaways said they were not reported missing to the police by parents or carers on the most recent occasion and a further 13\% were unsure (Rees, 2011). For children that are forced to leave, parents or carers are unlikely to report the child as 'missing' to police authorities. The use of data from professional services is also limited; only around one in twenty children sought help from professional agencies when away from home and many actively avoided contact with agencies (Rees \& Lee, 2005; Rees, 2011).

\section{Why do children run away or go missing from home?}

There can be many reasons why a child runs away or goes missing from home. The most common is difficult family circumstances (Biehal et al., 2003; Mitchell, 2003; NSPCC, 2007; Rees \& Lee, 2005; Rees, 2011; Safe on the Streets Research Team 1999; Wade 2001; Wade 2003). In a large scale English study involving self-reporting of 7349 children (aged 14 to 16), family environment was a significant factor in running away patterns. Almost a quarter (23\%) of children living in low-warmth, high-conflict family environments had run away overnight in the last twelve months, compared to only $2 \%$ in high-warmth, low-conflict family environments (Rees, 2011). The majority of young runaways who contacted the Message Home helpline cited 
family problems as a main reason, with around a quarter reporting alleged abuse (Mitchell, 2003). UK researchers explored the experiences of young people who are forced to leave home utilising the Still Running 2 dataset and monitoring data from six specialist runaway services (Rees \& Siakeu, 2004). Just over a quarter of young people $(26 \%)$ felt forced to leave home, mostly for reasons of abuse, violence and family conflict.

\section{What can happen when children run away?}

Children can face considerable risks to their safety when running away or going missing from home, including physical assault, sexual exploitation and engaging in criminal activity. The most recent survey of young people found one in eleven young people reported being hurt or harmed when away from home (Rees, 2011). One in six reported sleeping rough or staying with someone they had only just met. Almost one in eight said that they had stolen in order to survive and one in eleven said that they had begged.

Avoiding conflict at home as a result of behaviour or arrest was a rationale for a small number of children reported as missing to the National Missing Persons Helpline (Biehal et al., 2003). In Shalev's (2011) study of the criminal behaviour of 51 children who repeatedly ran away using police incident reports, shoplifting and theft were common arrests indicating 'survival strategies', as were battery, assault and grievous bodily harm.

Running away can be a protective measure for some children who face risks within their own homes. From interviews with fifty homeless youth in Los Angeles, Hyde 
(2005) critiqued the common construct of this group of young people as 'victims' and demonstrated young people's own narratives of agency in leaving home. Strategies for 'keeping safe' may include 'running to' the homes of trusted friends and family. Children living with parental problematic drug and alcohol often use friends and family as a place of safety at times of crisis (Bancroft et al., 2004, Houmøller et al., 2011). The majority of children who run away from home stay with friends and relatives (Rees \& Lee, 2005; Rees, 2011; Wade, 2001). However, there may still be considerable risks for this group; one sixth of young people were physically or sexually assaulted when staying with friends and one in twenty were assaulted when staying with relatives (Wade, 2001).

Children may be coerced into exploitative relationships that involve 'running away' from parents or carers to another person (Berelowitz et al., 2012). For some children, this is conceptualised as a romantic relationship with a boyfriend or girlfriend, leaving familes feeling powerless when their children are then sexually exploited. US studies have shown that young women who have been sexually abused in the family home are at an increased risk of further sexual abuse and exploitation when away from home (Tyler et al., 2013).

\section{Professional support}

Only a small minority of children have any contact with professional agencies during a running away episode. Children have limited knowledge about local services that could help; express concerns about trust and confidentiality, and worry about being returned home when running away (Rees et al., 2009). The Still Running 3 study found only $5 \%$ of children contacted a professional (most commonly social services 
or school staff), with the majority of children relying on informal support through friends, relatives and friend's families (Rees, 2011). The majority of children do not report that they have been hurt or harmed during the running away or missing episode. Whilst the experience of running away or going missing from home may be a time of fear and anxiety, it may also be a time of resourcefulness and independence (Rosenthal et al., 2006). Children may demonstrate significant strategies for managing and reducing the risks they face during this period; for the majority, their return to a safe environment may be a positive indication of their awareness of the potential risks.

Over half of children who had run away from home due to abuse wanted to contact social services (Mitchell, 2003). The Still Running 3 survey found a significant majority of young people actively avoiding contact with adults (Rees et al., 2011). Young people may avoid profession agencies due to a fear of being returned home and the potential consequences. In a study of young people's use of three telephone helplines (ChildLine, Message Home and Get Connected) both males and females valued 'more instrumental kind of help' addressing their immediate needs (Franks and Medforth 2005:79). Given the generally low rates of contacting professional services amongst young runaways, this finding indicates the value of intermediary accessible services in supporting children to contact formal agencies.

\section{CASE EXAMPLE: NSPCC Missing Children's Service}

The NSPCC is a leading children's charity in the UK working to end cruelty to children. NSPCC's work is focused on helping children in the greatest need, danger and distress and offers a range of evidence-based services designed to make the 
biggest difference possible. This illustrative case study was developed by NSPCC service managers in England and researchers based at the Child Protection Research Centre at the University of Edinburgh. An anonymised and password protected service dataset was provided for 2010-2011. Data were collated and analysed in a Microsoft excel programme. Approval was granted internally by NSPCC Services for Children and Families and analysis commenced during an intensive evaluation of all interventions for children during strategic review and detailed in the High Risk Families Report (Taylor et al., 2010). Prospective data collection would have been methodologically stronger, but this was not an option as the service was already running. It is therefore presented only as a case example.

Set up as a pilot service in 2009, the NSPCC Missing Children Service primarily worked with children who had been reported missing from home and who were not a current open case with Children's Social Care. The NSPCC service is provided in an urban area covered by one police authority. The majority of referrals were made directly by the police at the point of the child being reported missing, although selfreferrals or referrals from other professionals were also accepted. The police aimed to identify all children who were vulnerable as defined by National Indicator 71 (DCSF, 2009). This included: all children who had been reported missing on two occasions; and/or those who had been reported missing on at least one occasion and the incident was longer in duration than 24 hours or there were additional concerns including known mental health problems, engagement in criminal activity, known to be hurt or harmed whilst missing, at risk of sexual exploitation or in contact with a person posing a risk to children. This broader remit included children who had "run away," children who had been forced to leave home and children who were missing without 
their parent or carer's knowledge of their whereabouts.

When a missing person's report was received by the police, notifications were sent to the local authority safeguarding information team. If a child was already known to social care, the designated social worker was notified. All other missing notifications that were identified as needing a Return Interview Assessment were sent to the NSPCC via a secure email system. The NSPCC could also receive referrals from young people or other professionals. In most instances, these referrals were generated through work with a different young person. For example, the school may identify that the young person is going missing with a friend, but the friend has not been reported as missing to the police. Thus, the NSPCC sometimes indirectly led to an increase in missing notifications through identifying children who had previously not been reported missing.

Between April 2010 and March 2011, 152 children were referred to the service (59\% females, $41 \%$ males). The majority of children were aged between 13 and 15 years old $(\mathrm{n}=104)$. Twenty-one of the children were aged between 8 and 12 years old and twenty seven were aged between 16 and 17 years old. The majority of children were white British ( $\mathrm{n}=110)$.

The service provided two distinct functions that had been highlighted in the literature as offering considerable potential (Rees 2001): The first was to offer Return Interview Assessments to all children referred to the service. The second was to provide a programme of support to children who were assessed as having specific needs that related to the missing incident, that were not or could not easily be addressed through 
any other provider (for example, children at risk of sexual exploitation, children who made unsafe choices). All of the NSPCC workers who worked at this service were qualified social workers.

\section{The use of Return Interview Assessments}

Opportunities for children to talk confidentially following a running away or missing from home episode have been identified as an important safeguard (Burgess et al., 2010; Wade, 2003). Children need to feel they are not being judged (Taylor et al., 2013). The Statutory Guidance for children who have run away or have been missing recommends the use of Return Interview Assessments for children within 72 hours of returning home (DCSF, 2009). The Return Interview Assessment provided the child with the opportunity to talk about why they ran away and for their support needs to be identified. This was an early opportunity for professionals to ensure that children were given the space to be heard and were safeguarded effectively. The NSPCC could usually make contact with the young person within 72 hours. Delays were usually caused by practical issues e.g. incorrect mobile phone numbers. It was more problematic managing to meet with the young person within the 72 hours due to the tensions between prioritising the 72 hour target and using methods to approach the young person that were most likely to lead to them genuinely engaging, but may take longer to implement. For example, giving the young person a choice about when and where to meet or see a worker who they already knew. Overall, the approach used had positive results in terms of engagement.

The Return Interviews were usually completed at the family home, unless the young person chose to be seen at school or at the NSPCC centre. The worker would usually meet with the young person on their own, but also spend time with the young person 
and parents together. The Return Interview would usually require two visits: one to gather information and seek consents to talk to other agencies and one to feedback and discuss future support. Consent would be sought to gain information from other professionals e.g. teachers. The involvement of the parents in the Return Interview process could present challenges in building a relationship with the young person. However, young people consistently cited family difficulties as the central issue, thus engaging with the parents was considered important.

In the NSPCC service, Return Interview Assessments were conducted using the Common Assessment tool (Department of Health, 2003) to ensure that in addition to gathering information on the specific missing incident, broader information was collated relating to the child's welfare.

\section{The connection between the conduct of the interviews and the follow through} with support.

The following outcomes could be identified following the assessment.

1. Assessment completed and no additional needs identified so information provided only.

2. Assessment completed and needs already being met by other services.

3. Assessment completed and referral made to another service to meet needs (including social care).

4. Assessment completed and Missing Children's service to provide a workplan of support. 
A number of children were identified as not needing any ongoing support or they refused ongoing support. Lead workers in schools were notified if support was refused (consent permitting), so that they could revisit the support needs if further issues arose. If the young person had a repeat missing incident, this could be reassessed by the same NSPCC worker.

If the Return Interview Assessment identified that a referral was needed to another agency, then this could be made through the completed CAF assessment, avoiding the need for repeat assessments. If a need for ongoing support was identified and it could be provided, NSPCC aimed to offer the young person the same worker who had conducted the return interview. This continuity was considered to be a critical aspect to the engagement of the young person.

Overall, the method of completing a Return Interview Assessment as a Common Assessment was more time consuming. However, it aimed to ensure that the broad range of needs for that young person were considered and the young person, parents and other agencies were aware of what the support plan was following the missing incident.

As part of the Return Interview Assessment, the NSPCC collated information relating to the contributory vulnerability factors. Between the period 2010-2011, information on the vulnerability factors identified 111 children. The most prevalent needs identified included: Significant parental difficulties in managing their child's behaviour (70\%), problems at school (57\%), young person's emotional health $(53 \%)$ and significant family stress (e.g. parental mental health, disability, loss of significant family member) (47\%). For figures on all areas see Table 1. 
Insert Table One.

These needs were identified at the Return Interview Assessment stage given that children had been seen on only one or two occasions, it is probable that vulnerabilities relating to substance misuse or sexual relationships were underreported significantly. Assessments would typically reveal that "running away" from a stressful home environment had developed as a coping strategy for this group of children.

When the Return Interview Assessment identified additional or complex needs that were not currently being addressed and could not be addressed by the NSPCC service, a referral was made to targeted or specialist services. Referrals to social care contained the details gathered on the Common Assessment Framework assessments and in a team around the Child Plan. During the period 2010 - 2011, 24 children were referred to services provided by Children's Social Care. Of these, 11 referrals related to safeguarding concerns, the remaining referrals related to other children's social care services e.g. notification of a private fostering arrangement that required assessment. The referrals that were made in respect of safeguarding concerns all related to child neglect, although there may have also been specific additional concerns such as domestic abuse. All of these were accepted for at least an initial assessment. The decision to base all return interviews on a Common Assessment Framework document may have assisted in the success of these referrals being received due to a detailed assessment underpinning each referral. Equally, the connection between the Return Interview Assessment and ongoing support meant that the NSPCC was in a strong position to convey the sequence of safeguarding issues to 
avoid each one being viewed "in isolation". This was particularly important in evidencing concerns around neglect e.g. failure to protect, lack of supervision. It is not known whether the NSPCC's authorised status may have had an impact on the response to referrals during this time period as all referrals were accepted based on the information given. Whilst figures for referrals are relatively small, there was no information to indicate that it was those children who had the greater number of missing incident reports who were more likely to be referred for safeguarding concerns. The most significant concerns were for children with only one or two reported missing incidents, but the child had been missing on many more unreported occasions, indicating neglect.

\section{Provision of ongoing support}

The NSPCC provided a programme of support to children, if appropriate, following the assessment of need. This was only offered to children where the need identified would be best met through provision of the NSPCC service, rather than other targeted or specialist services e.g. Child and Adolescent Mental Health Services. The prevalence of vulnerability factors being related to either parental difficulties in managing behaviour and/or significant family stress meant that the programme of support frequently included some individual work with parents or carers. This would include support in developing alternative strategies for managing behaviour and helping parents to have the information and skills to recognise indicators of sexual exploitation and substance misuse. Children often responded well to the inclusion of parents or carers in some aspects of the work and some said that it challenged the common view that "they were always seen as the problem" and not their parents. 
The programme of support provided directly to children would also usually encompass a piece of work around recognising risks and making safer choices, e.g. enabling children to look at alternative decisions when they feel that they need to "run away" from the home environment, or recognising risks relating to issues such as sexual relationships, internet use and gang involvement.

\section{Discussion}

\section{Still a hidden group: a retracted lens}

There is a paucity of services for children and young people who run away from home or go missing (Rees et al., 2009; Rees et al., 2011; Smeaton, 2009). Despite the policy rhetoric, children who run away or go missing from home remain a hidden group in child welfare provision yet are known to have significant vulnerabilities (Taylor et al., 2013; Radford et al., 2011). Half of all local authorities in England did not have a policy for children missing from home compared to $93 \%$ had a policy for children missing from care; only $12 \%$ of local authorities had services targeted at young runaways and less than a third (29\%) provided emergency accommodation for young runaways in the local area (Evans et al., 2007). Although the Statutory Guidance (DCSF, 2009 and under current review) included promising intentions, the optional use of National Indicator 71 has subsequently been omitted. The lens of political focus has retracted to children missing from care, with the oversight of children missing from home. This is demonstrated in the House of Commons Inquiry exclusive focused on children missing from the care system (APPG for Missing Children and adults and APPG for Looked after Children and Care Leavers, 2012). However, many young people with care experiences began patterns of running away when still living

in the family home (Malloch 2006; Smeaton, 2009; Wade 2001; Wade, 2003). 
Improving the identification, assessment and support for children and families when running away from home could be part of an early intervention approach prior to young people entering the care system.

The case for early intervention in the early years has been well rehearsed (Allen, 2011) and few would need convincing. Early intervention in adolescence though is often overlooked (Rees et al., 2011). Increasing the protective factors around adolescents has been shown to be helpful in improving resilience (Scales et al., 2006). Daniel and colleagues (2011) advocate a public health approach to child neglect, where early intervention as soon as risk factors are recognised is as important as early intervention to allay and identify risk factors.

In addressing the multiple and complex needs of children who are forced to leave home, Rees and Siakeu (2004) argue that there needs to be a shift from a narrow focus on only short-term interventions (emergency accommodation and advocacy services) towards 'mediation, whole family approaches and longer term support'. Rosenthal and others (2006) highlight that homelessness services have focused on independent living skills rather than family reconciliation. They highlight the importance of understanding of the reasons why young people are leaving home to ensure effective and timely services. The role of Family Group Conferences (FGC) could be of value for young runaways given the most common reason for running away is due to family problems; there is some evidence supporting the work of FGCs where safeguarding concerns exist and children may be removed from family homes (Brown, 2003). In using a child and young person centred approach, family group conferences can 
provide a more inclusive, family-focused mediation space of benefit to children and their families (Barnsdale et al., 2007).

The value of independent assessments with young runaways to identify safeguarding concerns has been highlighted (Mitchell et al., 2012; Wade, 2003). There have been few evaluations of the effectiveness of Return Interview Assessments. The Grampian Police Return Home Welfare Interviews (RHWI) Pilot was developed to explore the effectiveness of delivering RHWI to improve outcomes for children (Burgess et al., 2010). The study found RHWI a useful intervention, particularly for children who were not already known to services. Children were generally positive about the RHWI experience; however, views were mixed on whether it had affected the likelihood of running away again. This indicates the importance of the Return Interview Assessment as a starting point to identify unmet needs and risks with the child and family to then develop a programme of work with the child and family or facilitate access to appropriate services.

\section{Conclusion}

Children who run away or go missing from home have often remained hidden from professional agencies with safeguarding responsibilities. Drawing on findings from an NSPCC service, this group of children are facing multiple challenges in their lives and need help to deal with these issues. Identification of need through the use of Return Interview Assessments provides a valuable early intervention approach for children who are rarely known to social care services. Creating multiple opportunities for children and young people to talk 'in confidence' about harm that may have been experienced both in the family home as well as during their time away from home, 
provides a valuable space to address safeguarding concerns. Fundamentally, all children have a right to effective, appropriate and timely support.

\section{Word count: 4998}

\section{References}

Allen G. 2011. Early Intervention: Smart Investment, Massive Savings. Cabinet Office: London.

Bancroft A, Wilson S, Cunningham-Burley S, Backett-Milburn K, Masters H. 2004. Parental drug and alcohol misuse: resilience and transition among young people. Joseph Rowntree Foundation: York.

Barnsdale L, Walker M. 2007. Examining the use and impact of Family Group Conferencing. Scottish Executive: Edinburgh.

Berelowitz S, Firmin C, Edwards G, Gulyurtlu S. 2012. 'I thought I was the only one. The only one in the world': The Office of the Children's Commissioner's inquiry into child sexual exploitation in gangs and groups - Interim report. Office of the Children's Commissioner: London.

Biehal N, Mitchell F, Wade J. 2003. Lost from view: Missing persons in the UK. The Policy Press: Bristol.

Brown L. 2003. Mainstream or margin? The current use of family group conferences in child welfare practice in the UK. Child and Family Social Work 8: 331-340. DOI: $10.1046 / \mathrm{j} .1365-2206.2003 .00293 . x$

Burgess C, Malloch M, Mitchell F, Chan V, Eunson J, Murray L. 2010. Grampian police return home welfare pilot for young runaways: a pilot evaluation. University of Stirling/Ipsos MORI Scotland: Stirling.

Chase E, Stratham J. 2005. Commercial and sexual exploitation of children and young people, Child Abuse Review 14: 4-25. DOI: 10.1002/car.881 
Daniel B, Taylor J, Scott J. 2011. Recognizing and helping the neglected child: Evidence based practice for assessment and intervention. Jessica Kingsley: London.

Department for Children, Schools and Families. 2009. Statutory guidance for children who run away or go missing from home and care: Supporting local authorities to meet the requirements of the National Indicator 71-Missing from home and care. DCSF: London.

Department of Health. 2003. Every Child Matters. Department of Health: London.

Evans K, Houghton-Brown M, Rees, G. 2007. Stepping up: the future of runaways services. The Children's Society: London.

Franks M, Goswami H. 2010. Rural runaways: rurality and its implications for services to children and young people who run away. Children and Society 24: 123-135. DOI:10.1111/j.1099-0860.2008.00202.x

Franks, M., \& Medforth, R. 2005. Young helpline callers and difference: exploring gender, ethnicity and sexuality in helpline access and provision, Child and Family Social Work 10: 77-85.

Gray D, Watt P. 2013. Giving Victims a Voice. Joint Report into Sexual Abuse Allegations made Against Jimmy Savile. NSPCC and MPS: London.

Houmøller K, Bernays S, Wilson S, Rhodes T. 2011. Juggling harms: coping with parental substance misuse. London School of Hygiene and Tropical Medicine: London.

Hyde J. 2005. From home to street: understanding young people's transitions into homelessness. Journal of Adolescence 28: 171-183.

DOI:10.1016/j.adolescence.2005.02.001

Khadr SK, Viner RM, Goddard A. 2011. Safeguarding in adolescence: underrecognised and poorly addressed. Archives of Disease in Childhood 96: 991994.

Malloch, M. 2006. Running - Other Choices: An evaluation of the ROC refuge. Aberlour Trust: Stirling.

Malloch M, Burgess C. 2011. Responding to young runaways: problems of risk and responsibility, Youth Justice 11(1): 61-76. DOI: 10.1177/1473225410394281

Mitchell F. 2003. Can I come home? The experiences of young runaways contacting Message Home helpline, Child and Family Social Work 8: 3-11.

DOI: $10.1046 / \mathrm{j} .1365-2206.2003 .00264 . x$ 
Mitchell F, Malloch M, Burgess C. 2012. The role of return home welfare interviews in responding to the needs of young runaways. Children and Society DOI:10.1111/j.1099-0860.2012.00467.x

NSPCC. 2007. ChildLine Casenotes: Running away and homelessness. NSPCC: London.

Raws, P. 2001. Lost youth: Young runaways in Northern Ireland. The Children's Society: London.

Radford, L, Corral, S, Bradley, C, Fisher, H, Bassett, C., Howat, N. and Collinshaw, S. 2011 Child cruelty in the UK 2011 - An NSPCC study into childhood abuse and neglect over the past 30 years. NSPCC: London.

Rees G, Franks M, Medforth R, Wade J. 2009. Commissioning, delivery and perception of emergency accommodation for young runaways. Department for Children, Families and Schools and The Children's Society: London.

Rees G, Lee J. 2005. Still running II: findings from the second national survey of runaways. The Children's Society: London.

Rees, G. 2001. Working with young runaways: Learning from practice. The Children's Society: London.

Rees, G. 2011. Still Running 3: Early findings of our third national survey of young runaways. The Children's Society: London.

Rees G, Siakeu J. 2004. Thrown away: The experiences of children forced to leave home. The Children's Society: London.

Rees G, Hicks L, Gorin S, Stein M. 2011. Adolescent Neglect: Research, Policy and Practice (Safeguarding Children Across Services). Jessica Kingsley: London.

Rosenthal D, Mallett S, Myers P. 2006. Why do homeless young people leave home? Australian and New Zealand Journal of Public Health 30(3): 281-285. DOI: $10.1111 /$ j.1467-842X.2006.tb00872.x

Safe on the Streets Research Team. 1999. Still running: children on the streets of the $U K$. The Children's Society: London.

Scales P, Benson P, Roehlkepartain E, Sesma A, van Dulmen M. 2006. The role of developmental assets in predicting academic achievement: a longitudinal study. Journal of Adolescence 29: 692-708.

Shalev K. 2011. Children who go missing repeatedly and their involvement in crime. International Journal of Police Science \& Management 13(1): 29-36. DOI:10.1350/ijps.2011.13.1.197

Smeaton E. 2009. Off the radar: children and young people on the streets in the UK. Sandbach: Railway children. 
Sullivan P, Knutson J. 2000. The prevalence of disabilities and maltreatment among runaway children. Child Abuse and Neglect 24(10): 1275-1288.

Taylor J.; Jerwood D.; Lazenbatt, A. 2010 Scoping Report: Physical Abuse in High Risk Families. NSPCC: London.

Taylor, J.; Bradbury-Jones, C.; Hunter, H.; Sanford, K.; Rahilly, T.; Ibrahim, N.(2013 early view) Young people's experiences of going missing from care: A qualitative investigation using peer researchers Child Abuse Review DOI: 10/1002/car.2297

Tyler K, Gervais S, Davidson M. 2013. The relationship between victimization an substance use among homeless and runaway female adolescents. Journal of Interpersonal Violence 28(3): 474-493. DOI: 10.1177/0886260512455517

Wade J. 2001. Missing out - Young runaways in Scotland. Aberlour Child Care Trust: Stirling.

Wade J. 2003. Children on the edge - patterns of running away in the UK, Child and Family Law Quarterly 15(4): 343-352.

Westminster All Party Parliamentary Group for Runaway and Missing Children and Adults and the APPG for Looked After Children and Care Leavers. 2012. Report from the Joint Inquiry into Children who go Missing from Care. APPG: London. 
Table One: Vulnerability factors identified in Return Interview Assessments

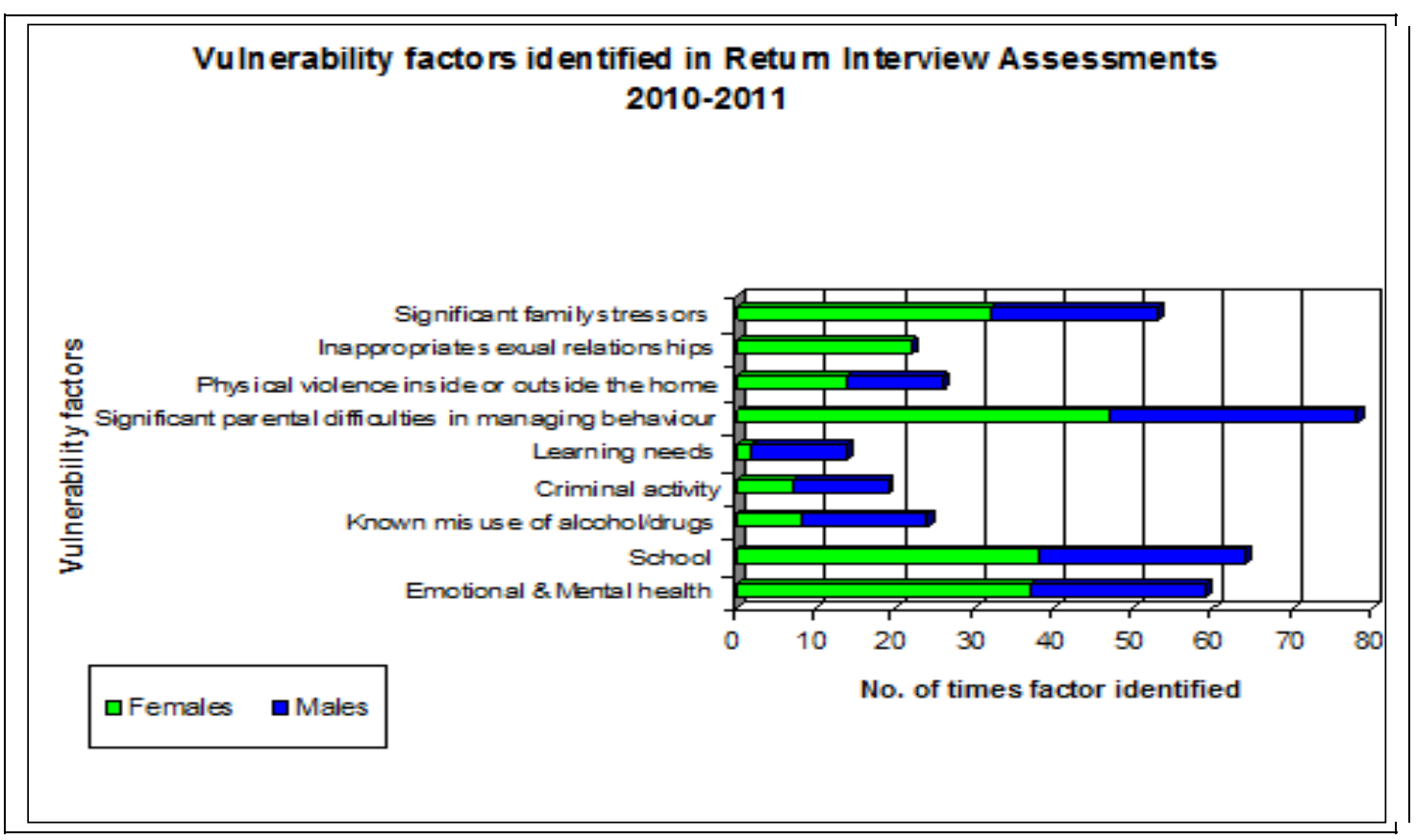

